\title{
Recordando a Alberto Ginastera en el centenario de su nacimiento en Buenos Aires, el 11 de abril de 1916
} A Recollection of Alberto Ginastera on the Occasion of the
Centenary of his Birth in Buenos Aires on April 11, 1916

\author{
por \\ Juan Orrego-Salas \\ Universidad de Indiana, Bloomington, Estados Unidos \\ jucar@ciswired.com
}

\begin{abstract}
El compositor chileno Juan Orrego-Salas, Premio Nacional de Artes Musicales 1992, hace un recuerdo de su amistad con Alberto Ginastera desde 1945, cuando ambos residieron junto a sus familias en Nueva York como becarios de la Fundación Guggenheim, además de sus encuentros ulteriores en festivales de música, escuelas de verano, estrenos de obras de Ginastera y su participación en proyectos institucionales afines. Incluye una consideración de las tendencias estilísticas de la obra de Ginastera, según se refleja en algunas obras representativas, y el valor estético de su música.
\end{abstract}

Palabras clave: música docta en Chile, Argentina y América Latina.

The Chilean composer Juan Orrego-Salas, recipient of the National Arts Prize in Music 1992, recollects his friendship with Alberto Ginastera since 1945, when both and their families resided in New York as recipients of awards of the John Simon Guggenheim Memorial Foundation. Besides Orrego-Salas gives an account of subsequent occasions when both were in direct or indirect contact-music festivals, summer schools, first performances of Ginastera's works and institutional projects. Orrego-Salas also discusses the stylistic tendencies in Ginastera's oeuvre, as they appear in some representative works, along with the aesthetic value of his music.

Keywords: classical music in Chile, Argentina and Latin America.

En la época que había iniciado, durante las primeras semanas de 1945, mi estada con Carmen, mi mujer, y mi hijo mayor, Juan Cristián, en Nueva York como becario de la Fundación Guggenheim, el Director General de esta organización, Henry Allen Moe, me comunicó que el compositor argentino Alberto Ginastera, también becario de esta fundación, se encontraba por llegar y me solicitó que lo apoyara en su manejo del idioma inglés. Acepté gustoso su pedido, aunque con cierta duda si mi manejo del inglés no era igualmente débil.

No tardamos en hacernos buenos amigos, y nuestras familias se conectaron con facilidad. Mi colega y su mujer Mercedes Toro, también conocida como Nata, sus hijos Álex y Georgina, y su cuidadora. Con frecuencia nos encontramos en conciertos, en museos y galerías de arte además de compartir cenas con amigos comunes. En una oportunidad en que fuimos invitados con mi mujer a pasar unos días fuera de Nueva York, Alberto y Nata se apresuraron a ofrecer el quedarse al cuidado de Juan Cristián en su casa.

En 1946 nos encontramos en el Festival de la Orquesta Sinfónica de Boston y en la Escuela de Verano de Tanglewood, junto a un grupo de compositores de las Américas 
seleccionados para asistir a las clases avanzadas de Aaron Copland. Entre ellos figuraban Héctor Tosar de Uruguay, Julián Orbón de Cuba, Antonio Estévez de Venezuela, Lukas Foss e Irving Fine de los Estados Unidos.

Así transcurrió este período de becarios, hasta que ambos regresamos a nuestros países de origen. Posteriormente nos volvimos a encontrar en los Festivales Interamericanos de Música, en Caracas, Washington, Montevideo, y en otras ocasiones en que se presentaban obras nuestras. Es así como asistí a la première de su ópera Don Rodrigo op. 31 (1963-1964) en la temporada inaugural del Lincoln Center de Nueva York, la que comenté extensamente en 1967 en la revista Hispanic Arts, editada por la Universidad de Indiana. Luego concurrí con mi esposa Carmen a la presentación de Bomarzo op. 34 (1966-1967), su segunda ópera, en el City Center de Nueva York.

Junto a sus obras tempranas, como las Suites de los ballets Panambi op. 1 (1934-1936) y Estancia op. 8 (1941), incluidas en las temporadas de la Orquesta Sinfónica de Chile bajo la dirección de los maestros Juan José Castro y Erich Kleiber, estas óperas o sus posteriores Estudios sinfónicos op. 35 (1967) y Variaciones concertantes op. 23 (1953) para orquesta me confirmaron que se trataba de un compositor original, de gran claridad de ideas e impulso.

No me ha sido posible conocer su tercera ópera Beatrix Cenci op. 38 (1971), la que se incluyó en la apertura del Kennedy Center de Washington. Barrabás, la siguiente de sus óperas, quedó sin completar por la temprana muerte de mi colega y amigo en Ginebra, Suiza, el 25 de junio de 1983. Pienso que la creación de su Sonata op. 48 para violonchelo y piano (1979) y su Concierto $\mathrm{N}^{\circ} 2$ op. 50 (1980) para violonchelo y orquesta, ambas obras dedicadas a su segunda esposa, la violonchelista Aurora Nátola, como su Puneña $\mathrm{N}^{\circ} 2$ op. 45 (1976), dedicada a Paul Sacher, y su resentida salud, le impidieron terminar esta ópera.

Sin embargo, me es posible establecer que nuestra amistad desde que nos encontramos en 1945 como becarios de la Fundación Guggenheim, no solo se extendió por medio de la música que ambos escribíamos, sino que más allá, gracias a varias otras coincidencias en nuestras vidas.

Fue así como en 1950 la Orquesta de Louisville nos solicitó a ambos participar en el programa de grabaciones de música contemporánea que este conjunto estaba realizando, Ginastera compuso su Pampeana No 3 op. 24 (1954) y yo mi Serenata concertante op. 40 (1954).

En 1961 la Fundación Rockefeller en asociación con la Escuela de Música de la Universidad de Indiana, en Estados Unidos, decidió establecer un centro de estudios y difusión de la música latinoamericana. Así nació el Latin American Music Center del que se me nombró su primer director. Luego, esta misma fundación norteamericana estableció en Buenos Aires el Instituto de Altos Estudios Musicales en conjunto con su correspondiente argentina, la Fundación Torcuato Di Tella. Este fue presidido por Ginastera, lo que le permitió materializar su idea de contribuir al desarrollo, conocimiento e investigación de la música de América Latina, en el norte y sur continental.

Del nacionalismo argentino inicial, propio a la tradición brasileña de Heitor Villalobos, mejicana de Silvestre Revueltas y Carlos Chávez, o la de Charles Ives y Aaron Copland en Estados Unidos, la obra de Ginastera se refleja en sus Pampeanas $\mathrm{N}^{\circ} 1$ op. 16 (1947) y $\mathrm{N}^{\mathrm{o}}$ 2 op. 21 (1950), sus Doce preludios americanos op. 12 (1944), o los Cantos del Tucumán op. 4 (1938). De ahí se mueve hacia una etapa que él mismo define como "neoexpresionista, de experimentación con la dodecafonía, la politonalidad y lo aleatorio". Esto se hace presente en sus Variaciones concertantes op. 23 (1953), Estudios sinfónicos op. 35 (1967), Iubilum op. 51 (1981), para orquesta, Turbae op. 43 (1974), para solistas, coro y orquesta, junto a sus últimas composiciones de cámara como en su excelente Cuarteto de cuerdas № 3 op. 40 (1973), con voz de soprano, sobre textos de Juan Ramón Jiménez, Federico García Lorca y Rafael Alberti. Más de una docena de partituras para el cine se agregan a sus obras de concierto en la década de 1950. Entre ellas se destacan Facundo, el tigre de los llanos (1952), 
Caballito criollo (1953), y Los maridos de mamá (1956), además de La doncella prodigiosa (1961), música incidental para teatro.

Ningún compositor de Latinoamérica ha recibido en vida un mejor reconocimiento. En su guía para la investigación de Alberto Ginastera, Deborah Schwartz-Kates establece la existencia de 56 tesis doctorales, 87 estudios breves en revistas, 15 entrevistas y 9 libros en español, inglés y alemán. A estos se agrega una buena cantidad de fonogramas de sus obras, por destacados solistas, conjuntos de cámara, orquestas sinfónicas y directores ${ }^{1}$.

Así transcurrieron sus 67 años de vida incluidos en el centenario que hoy se celebra, junto a los recuerdos y amistad que guardo en mi memoria.

1 Deborah Schwarts-Kates. Alberto Ginastera: A Research and Information Guide [Routledge Music Bibliographies]. Nueva York: Routledge, 2010. 